\title{
A Comprehensive Review for Emotion Detection Based on EEG Signals: Challenges, Applications, and Open Issues
}

\author{
Awf Abdulrahman ${ }^{1 *}$, Muhammet Baykara ${ }^{2}$ \\ ${ }^{1}$ Department of Information Technology, Duhok Polytechnic University, Duhok 42001, Iraq \\ ${ }^{2}$ Department of Software Engineering, Technology of Faculty, Firat University, Elazig 23119, Turkey
}

Corresponding Author Email: mbaykara@ firat.edu.tr

https://doi.org/10.18280/ts.380430

Received: 11 March 2021

Accepted: 25 July 2021

\section{Keywords:}

electroencephalogram, classification, emotion recognition, features extraction, EEG, FFT, DWT

\begin{abstract}
Emotion classification based on physiological signals has become a hot topic in the past decade. Many studies have attempted to classify emotions using various techniques, to discover human emotions accurately. This study focused on listing the most recent studies that have classified emotions based on electroencephalogram (EEG) signals. This study also focused on solving the problems and challenges facing researchers in emotion classification and EEG applications used in several fields. The plan of this study is based on a strategy with three aspects within specific rules: The first aspect is the methods; we chose studies that included new methods to extract features. The second aspect is the data sets. We tried to choose a study that classified the same data set. The third aspect is applications; we have listed many applications of the EEG in several areas. We concluded from this study that detecting human emotions using the EEG signals is one of the most reliable and widely used methods of detecting emotions in the past few years. Also, we have noticed that the EEG can detect human emotions, especially in psychiatry, for example, for epileptic patients whose emotions cannot be extracted using traditional methods such as facial expressions and tone of voice.
\end{abstract}

\section{INTRODUCTION}

Emotions play an important role in our daily life [1]. Emotion is the human response to what is going on around them of events in every moment. Interest in recognizing emotions has increased in the past two decades [2,3]. Because if a person can discover and organize his emotions, his life will become better [1]. Researchers have tried to develop theories of emotion detection and methods and techniques for detecting emotions [2, 4]. One of the most commonly used emotion detection methods is the emotion detection method based on physiological signals received from the brain (EEG) [1]. This method raised the efficiency of emotion detection due to the reliability obtained from physiological signals. A person cannot control his inner emotions and the signals collected from his brain. Therefore, the interaction between humans and machines in the field of emotion detection has become a very hot topic for psychologists, medical scientists, and researchers in computer science $[1,5]$. There is no agreement about the nature of emotions among psychologists, neuroscientists, and other researchers, as there are two different views of emotions among scientists: the first opinion considers emotion as a general state of individuals, and the other opinion considers emotion as a physiological and physical interaction [6]. For example, if a person is in a forest and suddenly a predator appears in front of him, then according to the first opinion, he will feel fear because he knows that this animal will prey on him. As for the second opinion, the appearance of a predator in front of the person leads to an acceleration of the heartbeat and blood pressure, which generates a feeling of fear due to the brain's response [6]. Emotions can be classified according to three basic theories, namely: Plutchik's theory, Ekman's theory, and James Lange's theory [6-9]. Emotions are classified according to Pluchik's theory into two categories. The first section is called basic emotions, which contains the following emotions: anticipation, joy, confidence, sadness, fear, surprise, anger, disgust, and the second section is called secondary emotions, and it is a combination of basic emotions such as aggression, submission, contempt, dread, and others [6]. As for the classification of emotions based on Ekman's theory [8] (the discrete model theory), This theory presented 6 of the basic emotions: sadness, happiness, anger, disgust, fear, and surprise [6, 8]. As for James and Lange theory [9], it classifies emotions into a two-dimensional space called the arousal-valence model, in which valence is from unpleasant (negative) to pleasant (positive), and arousal from passive (low) to active (high) $[2,6,9]$, as in Figure 1 [10].

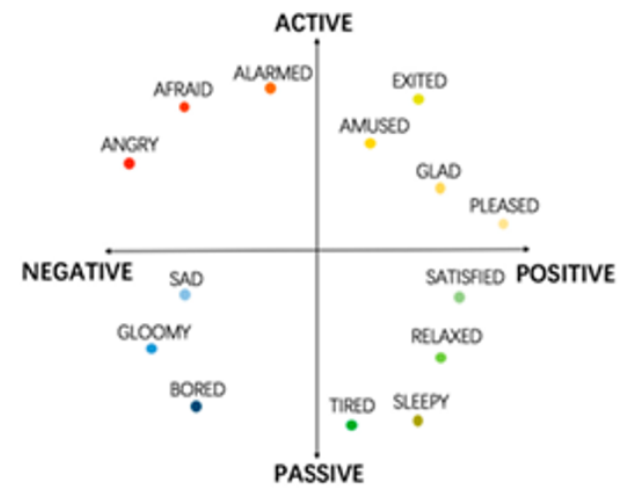

Figure 1. James and Lange theory (2-D space) [10] 
The rest of the sections of this study, the second section (An electroencephalogram), where a brief explanation was given about the device used to collect the data. The third section (previous Works), where the most important previous studies were listed. The fourth section (Public Data sets in the literature) summarizes a group of emotion databases. The steps for implementing this study are explained in the fifth section (stages of this study). The sixth section (methods in the literature) lists the most important methods used in the literature to detect emotions based on EEG. In the seventh section (Challenges and future works), more challenges and problems that may face researchers in classification emotions are listed. And the last section is a conclusion.

\section{AN ELECTROENCEPHALOGRAM (EEG)}

An electroencephalogram (EEG) collects data from a person by placing a wearable device around the head in a noninvasive manner, as in Figure 2 [11]. This device contains electrodes that are placed around the head according to the 1020 system $[12,13]$, as shown in Figure 3 [13]. This device monitors brain activity and records signals from the brain. These devices transfer the recorded signals to computers via wired, wireless, or other communication [12]. Then researchers and scientists analyze that data to make the conclusions they want.

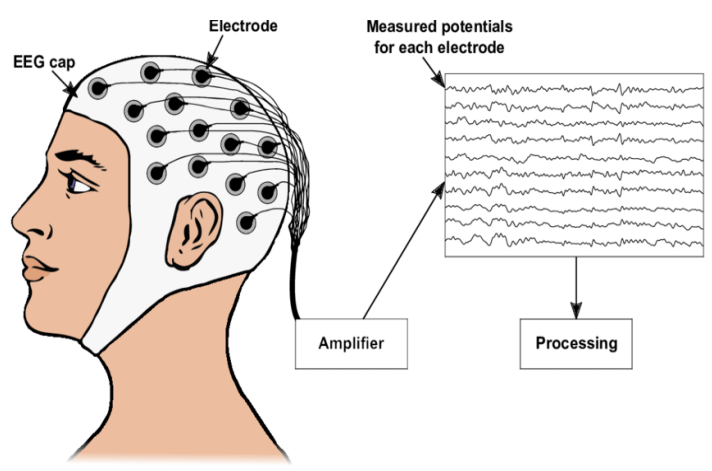

Figure 2. EEG device components [11]
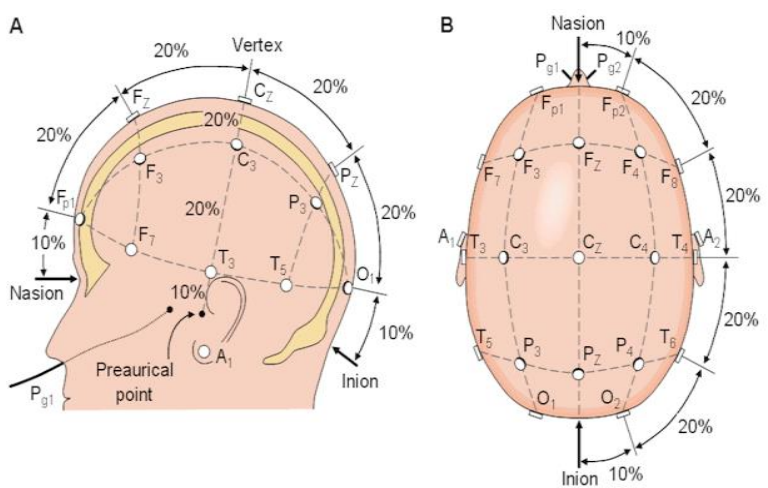

Figure 3. The 10-20 system a) front side b) topside

Electroencephalography (EEG) is an easy and inexpensive way that has been used to record brain activity and has also demonstrated that it is through brain activity that emotions can be detected [14]. Measuring brain activity via EEG devices has helped scientists understand the persons' emotions with disabilities whose emotions are difficult to detect through their facial expressions [15].
The process of classification emotions via the EEG passes through several primary and sequential stages, as in Figure 4. In the first stage (data collection stage), the type of stimuli that will be used to classify emotions (Visual stimuli such as viewing pictures, aural stimuli such as listening to music, or aural/visual stimuli such as viewing videos) watching film clips) is chosen. Then the number of people whose brain activity will be recorded and the number of EEG channels through which the signal will be collected is determined. Next, data is recorded from the brain as the subjects interact with the stimuli we mentioned. In the second stage (pre-processing stage), after collecting data from people, raw data is processed (pre-processing), for example, removing noise from the signal, reducing or increasing the number of samples, and dividing the signal into training data and test data, this stage helps in filtering data to improve results. In the third stage (feature extraction stage), features are extracted from pre-processed data, the techniques are used to extract features from EEG preprocessing signals, for example, fast Fourier transform (FFT), discrete wave transform (DWT), and statistical feature method (SF), and so on. This stage helps extract features from the original data that gives the classifier the ability to classify emotion accurately. In the fourth stage (classification stage), the classifiers that will classify the emotions are selected. The number of classes to be classified must be determined at this stage (i.e. two classes, three classes, or four classes), depending on the model used (arousal-valence model, negative and positive emotions model). In the fifth stage (The results) in this stage, the model that has been trained is evaluated.

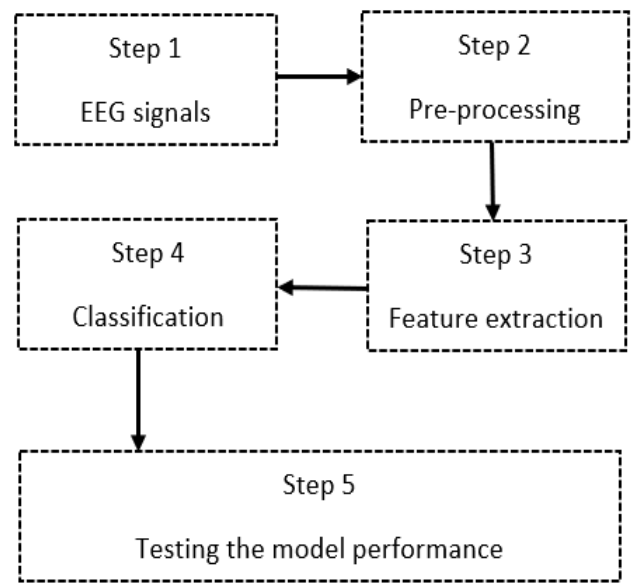

Figure 4. The 10-20 system a) front side b) topside

\section{PREVIOUS WORKS}

Alakus et al. introduced a new, freely available dataset based on physiological brain signals (EEG) and computer games as visual/aural stimuli called GAMEEMO to classify four emotions: boring, calm, horror, and funny. Their experiment was conducted with the participation of 28 subjects. Data were collected using a wearable and mobile device called EMOTIV EPOC with 14 channels. Then the research team tested a dataset data that they collected by using different methods to extract features, including statistical method, DWT, Hjorth features, Shannon entropy, and others, then used three machine learning classifiers: MLPNN, SVM, K-NN to classify two models of emotion detection models: 
Negative and positive model, and Valence-Arousal model [2]. Chao and Liu suggested a method using a deep beliefconditional random field (DBN-CRF), integrated with an improved deep belief network with glia chains (DBN-GC), to classify three emotion datasets: DEAP, SEED, and AMIGOS. Initially, the research team extracted the features in three ways: Time domain, frequency domain, and Time-Frequency domain [16]. Sharan et al. suggested a method for detecting personality traits using EEG signals. They used the IAPS image dataset and the English version of the FilmStim video dataset as stimuli to collect data from 18 individuals. Then, they used an inter-hemispheric asynchrony technique to extract the features, and then four machine learning classifiers were used (KNN, LG, NB, and SVM) to classify 16 personal traits [17]. Priya et al. introduced a method for classifying stress during work stress. The team selected a physio bank database in their experiment. First, they extracted the features using PSD technology and then used two machine learning classifiers (KNN and SVM) [18]. Tao et al. proposed a new method for classifying emotions using an attention-based convolutional recurrent neural network (ACRNN) where the team applied this method to the DEAP and DREAMER dataset [19]. Gao et al. proposed a new approach by combining the Granger Causality Method (GC) and the Histogram of Oriented Gradient (HOG) method to extract features and then using the Support Vector Machine Classifier (SVM) two types of emotions were classified: stress and calm [20]. Hassan et al. used the Unsupervised Deep Belief Network (DBN) to extract features from the DEAP physiological dataset. They then combined the features extracted from DBN with statistical features such as EDA, PPG, and zENG. They used the fine gaussian support vector machine (FGSVM) algorithm to classify five basic emotions [21]. Yang et al. present an approach based on a multi-column $\mathrm{CNN}$ algorithm to classify the emotions based on EEG signals taken from the DEAP database. The research team achieved a performance accuracy of $90 \%$ [22]. Xing et al., used a new approach to extract features from EEG signals, used the Long Short-Term Memory Recurrent Neural Network (LSTM-RNN) to build a linear EEG mixing model and an emotion timing model using a Stack AutoEncoder (SAE). This model was applied to the DEAP dataset to classify emotions, and the team obtained a performance accuracy of $81.10 \%$ in valence and $74.38 \%$ in arousal [23]. Martínez-Rodrigo et al. studied two nonlinear indices to classify emotion (emotional states of calm and negative stress) based on the brain's physiological signals: CMAAPE and CMQSE. This study applied the DEAP dataset to classify calm and negative stress, and they used two machine learning classifiers: SVM and DT. Then, they assessed the differences between the entropy values for each time scale of the calm states and negative stress for both indicators using the statistical method in addition to the analysis of variance (ANOVA) [24]. Salama et al., proposed a new, multimodal approach to classifying human emotions. They used a three-dimensional convolutional neural network (3D-CNN) to extract features from electroencephalogram (EEG) signals and video data of human faces. Then they built three methods of classifying emotions: the emotion recognition approach based on EEG signals, the face-based emotion recognition approach, and the fusion-based emotion recognition approach. In the first approach based on EEG signals, the team used 3D-CNN to obtain final predictions of EEG signals using the arousal-valence model [25]. Goshvarpour and Goshvarpour built a new approach to extract nonlinear features to classify emotions based on physiological brain signals (EEG). They studied a physiological DEAP dataset. This approach relied on feature minimization by using three algorithms to reduce features: random subset feature selection (RSFS), sequential floating forward selection (SFFS), and sequential forward selection (SFS), and an SVM classifier to classify valence-arousal emotions [26]. Liao et al. proposed an approach based on a convolutional recurrent neural network to classify emotions, in which two methods were used to identify features: the convolutional neural network for spatial representations of EEG signals and the LSTM algorithm for the temporal representations of EOG, EMG, GSR, RSP, BVP, and TMP signals. This study was applied to the DEAP dataset, which is of interest to us in this study is the first method based on the EEG signals, they used three consecutive twodimensional convolutional layers $(2 \mathrm{D}-\mathrm{CNN})$ to extract the features, and each layer has the same size of the nucleus $3 \times 3$ [27]. Cui et al, present a new approach based on the RegionalAsymmetric Convolutional Neural Network (RACNN) to classify valence-arousal emotions based on EEG signals downloaded from the DEAP and DREAMER dataset. Their study focused on extracting temporal, regional, and asymmetric features, where they used continuous onedimensional Convolutional layers in the temporal feature extractor, and then two two-dimensional Convolutional layers to capture regional information. Then they proposed an asymmetric differential layer (ADL) to extract the asymmetric characteristic of emotion between the left and right lobes of the brain. Their model achieves an average accuracy of over $95 \%$ with both datasets [28]. Ma et al, presented a method based on a multimodal residual LSTM (MMResLSTM) to classify arousal-valence emotions based on EEG brain signals. The DEAP dataset was used, which is from the important emotion datasets. They reduced EEG samples, removed impurities, computed average signal, and so on. Then they applied some feature extraction methods. for example, $\mathrm{db} 4$ discrete wavelet transforms, wavelet entropy, and wavelet energy features. Finally, they obtained a classification accuracy of $92.87 \%$ for arousal and $92.30 \%$ for valence [29]. Tripathi et al. used two neural network techniques (deep learning) to classification emotions: a simple deep neural network (DNN) and a convolutional neural network (CNN). They also used a statistical method to extract features [30]. Alakus et al. analyzed a GAMEEMO dataset based on physiological brain signals (EEG) to classify the negative and positive emotions model. The research team used the spectral entropy values of all EEG channels to extract the features, then used the bidirectional long-short term memory algorithm for deep learning to classify the emotions, finally, using the receiver operating system. characteristic (ROC) curve to evaluate the performance of the algorithm used [31]. Tarnowski et al. presented an experiment to analyze the galvanic skin response (GSR) and electroencephalogram (EEG) signals. Twenty-seven people participated in their experiment, where they were shown 21 short film clips, and then their emotions were classified based on the arousalvalence model. The team used a fast Fourier transform (FFT) method to extract features from the EEG signal, and two machine learning classifiers were used: SVM and k-NN [32]. Al-Nafjan et al, the research team chose the Deep Neural Network (DNN) to classify emotions based on the EEG. they used the DEAP database with two feature extraction methods: power spectrum density (PSD) and frontal asymmetry features. The approach they chose was efficient at $82 \%$ accuracy [33]. 
As can be understood from the studies in the literature, it has been seen that human emotions based on EEG signals can be found with high accuracy with various deep learning algorithms. Similarly, machine learning methods often give high success rates. It is seen that the DEAP dataset is generally used in studies. This dataset has a usage rate of more than $85 \%$. The repetition of studies with different methods based on a single data set and similar stimuli does not add any scientific innovation to the literature. For this reason, it should be emphasized that new EEG datasets like GAMEEMO are needed to overcome this weakness.

\section{PUBLIC DATASETS IN THE LITERATURE}

There are many emotion databases freely available to the public that anyone can download and analyze without the need for someone's approval or the participation of an organization in his work [6]. We will describe some general datasets for emotion detection based on EEG signals, as in Table 1.

\subsection{GAMEEMO Dataset}

The GAMEEMO database is an emotion dataset based on brain physiological signals (EEG). This dataset was recorded by Alakus et al. [2], conducted with the participation of 28 subjects at Firat University, Department of Software Engineering. The age range of the subjects used in the study is between 20-27 years old. It was not specified how many of the subjects used in the study were women and men. Data were collected from the participants using four computer games as stimuli to extract the four basic emotions (boring, calm, horror, and funny) for 5 minutes. A total of 20 minutes long EEG data was available for each subject. Data were collected through 14 channels using the EMOTIV EPOC + Mobile EEG wearable device. 38252 samples were collected from each participant and for each game [2].

\subsection{DEAP Dataset}

It is a dataset of emotions recorded by Koelstra et al. [34] in which an arousal-valence model was used with 40 video clips as stimuli. This experiment was carried out in two laboratories, Geneva and Twente, in 2012, where 32 people participated in this experiment. Data were collected for 32 EEG channels, in addition to 4 EMG channels, 4 EOG signals, 2-channel GSR signals, 2 ERG signals, temperature, respiratory rate, and blood pressure. Five emotions were recorded: arousal, valence, liked or disliked, familiarity, and dominance [6, 34].

\subsection{MAHNOB-HCI Dataset}

MAHNOB-HCI is a multimedia database recorded by Soleymani et al. In 2012 [35]. Data were collected from 27 individuals while they viewed 20 videos and photos. The data collected are EEG signals (32 channels), ECG signals (3 signals), ERG (2 channels), GSR (2 channels), respiratory capacity, and skin temperature signals. This experiment went through two parts. In the first session, the participants were asked to watch video clips, and then they were asked to fill out a questionnaire about their emotions after watching the videos. At the same time, in the second session, the videos and pictures were shown once with right and wrong labels and once without labels [35].

\subsection{SEED Dataset}

Zheng and Lu [36] recorded SJTU's EEG dataset (SEED), a physiological dataset collected from 15 individuals while they watched the videos. The dataset was recorded to classify three types of emotions, positive, negative, and natural. Participants were asked to fill out a questionnaire after watching the videos. The EEG was recorded in three separate sessions. There was a week or more between one session and another, and the EEG signals were recorded according to the international standard system $10-20[6,36]$.

Table 1. Different kinds of emotion datasets

\begin{tabular}{|c|c|c|c|c|c|}
\hline Dataset & Stimuli & Sub. & EEG & Emotion & Ref. \\
\hline \multirow[b]{2}{*}{ GAMEEMO } & \multirow[b]{2}{*}{4 Video Game } & \multirow[b]{2}{*}{28} & \multirow[b]{2}{*}{14 EEG signals } & Arousal-valence & {$[2]$} \\
\hline & & & & $\begin{array}{l}\text { Positive and } \\
\text { Negative }\end{array}$ & {$[31]$} \\
\hline \multirow{4}{*}{ DEAP } & \multirow{4}{*}{40 Video clips } & \multirow{4}{*}{32} & \multirow{4}{*}{$\begin{array}{c}32 \text { EEG, } 4 \text { EMG, } 4 \text { EOG, } 1 \text { GSR, } 1 \\
\text { RR }\end{array}$} & Arousal-valence & $\begin{array}{c}{[16,19,22,23,} \\
25]\end{array}$ \\
\hline & & & & stress and calm & {$[20]$} \\
\hline & & & & negative stress & [24] \\
\hline & & & & stress recognition & [37] \\
\hline $\begin{array}{l}\text { MAHNOB- } \\
\text { HCI }\end{array}$ & $\begin{array}{l}20 \text { Video clips and } \\
\text { Pictures }\end{array}$ & 27 & $\begin{array}{c}16 \text { EEG, } 3 \text { ECG, } 2 \text { GSR, } 1 \text { RR, } 1 \\
\text { Temp }\end{array}$ & Arousal-Valence & [38] \\
\hline SEED & 15 video clips & 15 & 15 EEG signals & Arousal-Valence & {$[16]$} \\
\hline
\end{tabular}

\section{THE METHODS IN THE LITERATURE}

There are many methods and techniques used in analyzing a data set of different emotions based on the physiological signals in the literature. In this study, we will summarize the latest methods and techniques used to classifying emotions in the literature, as in Table 2.

\subsection{Discrete Wavelet Transform (DWT)}

DWT is an important and widely used method for analyzing time-frequency signals in different frequency bands with different resolutions due to its unstable properties. The DWT decomposition of a signal uses a high and low pass filter, where DWT analyzes the signal into detailed and approximate information. The first decomposition in the DWT is considered in the approximation and detailed coefficients (A1, D1) to get the level 1 band, then A1 is decomposed into the approximation and detailed coefficients (A2, D2) again. Thus decomposition continues to a specified number of times [3942], as in Figure 5. 


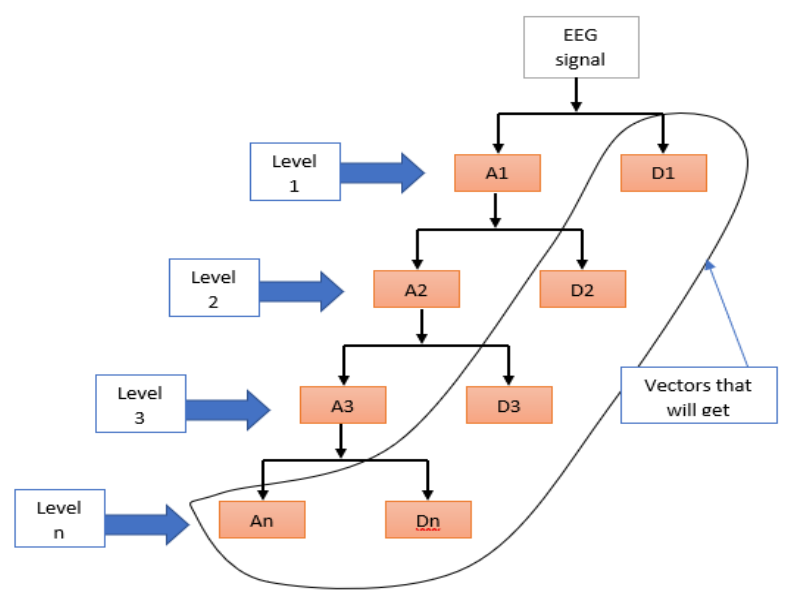

Figure 5. DWT sub-bands decomposition

\subsection{Fast Fourier Transform (FFT)}

The Fast Fourier Transform (FFT) is an algorithm that decomposes a complex signal into smaller transformations, using a discrete Fourier transform (DFT) for a sequence and an inverse (IDFT) [32, 43, 44]. FFT is one of the most used algorithms in signal analysis [45]. As for the features that are extracted based on FFT, they depend on decomposing the original signal into smaller transformations. Then, to obtain the resulting signal, the decaying signals are combined with the decaying signals and removing the low-frequency signals [43-45].

\subsection{Statistical Features (SF)}

The method of mathematical-statistical analysis is applied to the signal to obtain more information about this signal, such as the mean, median, deviation, kurtosis, standard deviation, skewness, minimum, maximum, and others [46]. To clarify the impact of statistical features on the final results of the model, we will use the study [47] as a reference. In this study, emotions were classified using the statistical feature method. The study was divided into three stages: In the first stage, three statistical features were extracted (minimum value, maximum value, and the mean). The model was trained using only the three features and achieved an accuracy of $2.03 \%$. Then, four other features were extracted (Variance, Standard deviation, Wave entropy, and Power bandwidth). The model was trained again using the new features and the old ones, and it achieved an accuracy of $32.14 \%$. We note the impact of adding additional features on the results. Then, in the third stage, two additional features were extracted (Skewness and Kurtosis), and the model achieved an accuracy of more than $92 \%$. To calculate mean, median, and stander deviation, we will use the equations as in Figure 6.

\subsection{Deep learning methods (1D, 2D, and 3D-CNN)}

The Convolutional neural network (CNN) algorithm is used to extract additional features from the raw data of the EEG signal in several recent studies, for example:

Ding et al. [48] constructed a one-dimensional convolutional neural network (1D-CNN) to extract the features. This network consists of 3 sequential segments: the temporal learner consisting of an EEG input segment (4 EEG channels $* 1024$ data points for each channel $* 1)$, the spatial learner consisting of $(4 * 9)$, and the classifier [48].

Liao et al. [27] used three two-dimensional Convolutional neural networks (2D-CNN) to extract the features. Each of these layers is composed of a core of equal size $(3 \times 3)$. The first layer also consists of 64 feature maps, the second layer 128 , and the third layer 256 feature maps [27]

Salama et al. [25] used a three-dimensional Convolutional neural network (3D-CNN) as a deep learning technique. Six basic layers are used to extract features and train the model. It is the input layer, followed by two 3D convolutional layers. After each 3D layer, there is a max-pooling layer and then the last layer, the feature extraction layer [25].

Wang et al. [49] presented a novel approach to automatically detect human emotions based on a Residual block-based deep convolutional neural network (CNN) to extract features and classify emotion using EFDMs automatically.

Wen et al. [50] proposed an end-to-end model based on convolutional neural networks (CNNs) to improve feature extraction performance based on EEG signals. Pearson's correlation coefficient first rearranged the original EEG channels. Then fed the rearranged EEGs into the CNN.

$$
\begin{aligned}
& \text { mean }=\frac{1}{n_{e}-n_{s}} \sum_{i=n_{S}}^{n_{e}-n_{s}} x_{i E E G} \\
& \text { Where: } \\
& n_{e} \text { : ending point of the sample. } \\
& n_{s} \text { : starting point of the sample. } \\
& n_{e}-n_{s}: \text { the total number of samples. } \\
& \text { median }=\left\{\begin{array}{cc}
x_{\frac{1}{2}\left(n_{e}-n_{s}+1\right)} & \text { if } n \text { is odd } \\
\frac{1}{2}\left(\frac{x_{\frac{n_{e}-n_{s}}{2}}+x_{\frac{n_{e}-n_{s}}{2}+1}}{2}\right) & \text { if } n \text { is even }
\end{array}\right. \\
& \text { Stddev }=\sqrt{\frac{1}{\left(n_{e}-n_{s}\right)-1} \sum_{i=n_{s}}^{n_{e}-n_{s}}\left(x_{i E E G}-\bar{x}_{E E G}\right)^{2}}
\end{aligned}
$$

Figure 6. Some Statistical equations [46]

\subsection{Short-Time Fourier Transform (STFT)}

The STFT method is one of the methods for converting the time domain signal into the time-frequency domain. This method combines the time domain and frequency domain in the signal analysis [45] to track the low energy level present in the original signal. This method has the advantage of adapting the Fourier transform to analyze only a small section of the signal at a given time. STFT splits the signal into small sequential or nested data frames, in contrast to the FFT method applied to all data frames [51]. For this reason, the STFT method is more efficient than the FFT method if the amount of data is large [45].

\subsection{Power Spectral Density (PSD)}

The Power spectral density (PSD) method is an important method to extract features from EEG physiological signals. It has been extensively studied to classify emotions because it is a good way to process narrow-band fixed signals, as it expresses the activity of each of the EEG signal bands (delta, theta, alpha, beta, and gamma) $[52,53]$. 


\subsection{Asymmetry in frequency for electrode Pairs (Based on PSD)}

The features are extracted in this way by subtracting the absolute PSD values of the poles of the right lobe of the brain from the absolute PSD values of the poles of the left lobe [54]. If we use, for example, 14 channels in the experiment, that is, we have seven pairs of electrodes, and the features that we will get are equal to $7 *$ the number of frequency points.

\subsection{Histogram of oriented gradient method (HOG) + Transfer Entropy (TE)}

It is a method by which a combination of TE and HOG is to extract features from the signal. Arrays are created using the TE technique that may contain an amount of duplicate data. Therefore, the HOG method extracts features from the TE matrix $[20,55]$.

Table 2. Different kinds of emotion methods in the literature

\begin{tabular}{ccc}
\hline Methods & Emotion & References \\
\hline DWT & $\begin{array}{c}\text { Happy, and sad } \\
\text { emotion }\end{array}$ & {$[41]$} \\
SF & Arousal-valence & {$[2,38,30]$} \\
& Relax, Stress & {$[56]$} \\
FFT & stress recognition & {$[37]$} \\
& Arousal-valence & {$[32]$} \\
STFT & Arousal-valence & {$[57]$} \\
& Arousal-Valence & {$[16,33]$} \\
PSD & Relax, Stress & {$[56]$} \\
& 5 Emotions & {$[21]$} \\
Asymmetry in & negative emotions & {$[58]$} \\
frequency & negative emotions & {$[58]$} \\
HOG + TE & Arousal-valence & {$[20]$} \\
3D-CNN & Arousal-valence & {$[25]$} \\
2D-CNN & Arousal-valence & {$[59]$} \\
1D-CNN & Arousal-valence & {$[48]$} \\
\hline
\end{tabular}

\section{CHALLENGES, APPLICATIONS, AND FUTURE WORKS}

\subsection{Applications}

Many applications have used the EEG in several fields, including the brain-computer interface (BCI), such as robot control applications [60], and applications used in smart homes to monitor and control sensors [61]. Ergonomics and biometrics, such as applications of human voice and face measurement [62]. Neuroscience [63], such as epilepsy [64], schizophrenia [65]. Customized solutions, such as health applications, monitor patient health [65] and educational applications [66]. Neuromarketing is like applications that analyze customer sentiments for a particular product and not others [67].

\subsection{Challenges and future works}

The ability to detect emotions based on physiological signals is one of the most fundamental topics in emotion classification. There are many ways to detect emotions, including facial expressions, writing, voice, and EEG signals. Because EEG signals are internal signals from the brain that a person cannot control, the challenge has increased for psychologists, computer science researchers, and others. The big challenge is finding the best methods that can be used to classify feelings based on EEG signals accurately. And the second challenge is a noise problem in the signal and in the low-frequency bands, where raw data processing is very complex to remove noise from the signal. Several techniques have been used in the data filtering process: Finite Impulse Response (FIR) filters, Adaptive Filter, Bandpass Filter, etc.

Another challenge is to reduce the input features' dimensions, handle the data with ease, and the unstable performance of the EEG [49].

Table 3 shows the advantages and disadvantages of an EEG. Table 4 shows the advantages and disadvantages of some of the most frequently used feature extraction methods in the literature.

The final challenge is choosing a suitable classifier for detecting emotions because there is an apparent discrepancy between the performance of the classifier and the performance of another in the same data set. When we conducted this study, we noticed that deep learning techniques such as DNN, 3DCNN, LSTM, BiLSTM and MMResLSTM were frequently used in the literature in recent years. We recommend using deep learning techniques with the WPD method to classify emotions in future work because WPD is suitable for nonstationary signals.

Table 3. The advantages and disadvantages of the EEG

\begin{tabular}{|c|c|c|c|}
\hline Advantages & & Disadvantages & Ref. \\
\hline $\begin{array}{l}\text { High Temporal resolution. } \\
\text { Safe and easy technique. }\end{array}$ & $\begin{array}{l}\bullet \\
\text { signals. } \\
\bullet \\
\bullet\end{array}$ & $\begin{array}{l}\text { Sensitive to EOG and ECG } \\
\text { Low spatial resolution. } \\
\text { Nonstationary signal. }\end{array}$ & [68] \\
\hline $\begin{array}{l}\text { - } \quad \text { Cheap and easy to use. } \\
\text { No multi-Tesla magnets or antimatter-producing radioisotopes are required just } \\
\text { wires and signal processing gear. }\end{array}$ & $\begin{array}{l}\bullet \\
\text { EEG. }\end{array}$ & An inverse problem plagues & [69] \\
\hline $\begin{array}{l}\text { - } \\
\text { - } \\
\text { Venfidential. } \\
\text { Impossible to steal. } \\
\text { - } \\
\text { EEG exists in every person and requires recording. }\end{array}$ & & $\begin{array}{l}\text { Noise } \\
\text { Nonstationary signal. }\end{array}$ & [70] \\
\hline
\end{tabular}


Table 4. The advantages and disadvantages of the features extraction methods based on EEG

\begin{tabular}{|c|c|c|}
\hline Method & Advantages & Disadvantages \\
\hline $\begin{array}{l}\text { Independent Component } \\
\text { Analysis (ICA) }\end{array}$ & $\begin{array}{l}\text { - } \\
\text { - } \\
\text { It showputationally efficient. } \\
\text { - } \quad \text { It decomposes signals into temporal } \\
\text { independent and spatially fixed components. } \\
\text { - } \quad \text { Computationally efficient } \\
\text { - } \quad \text { High performance for large data sized }\end{array}$ & $\begin{array}{lccc}\text { - It can't be } & \text { applicable } & \text { for } \\
\text { underdetermined cases } & & \\
\text { - Requires more } & \text { computations } & \text { for } \\
\text { decomposition. } & & & \\
\text { Require more } & \text { computational } & \text { for } \\
\text { decomposition } & & & \\
\end{array}$ \\
\hline $\begin{array}{l}\text { Principal Component } \\
\text { Analysis (PCA) }\end{array}$ & $\begin{array}{l}\text { Dimension reduction without losing data. } \\
\text { - } \\
\text { It helps in the reduction of feature dimensions. } \\
\text { classification of data }\end{array}$ & $\begin{array}{l}\text { Unable to process the complicated set of } \\
\text { Not well as ICA. }\end{array}$ \\
\hline Adaptive Filtering & $\begin{array}{l}\text { - Ability to modify the signal features according } \\
\text { to signals being analyzed. } \\
\text { - } \quad \text { Works well for the signals and artefacts with } \\
\text { overlapping spectra nature. } \\
\text { - } \quad \text { Works well for the signals with overlapping } \\
\text { spectra }\end{array}$ & Needs two signals (including reference \\
\hline $\begin{array}{c}\text { Wavelet Packet } \\
\text { Decomposition (WPD) } \\
\end{array}$ & Able to analyze the nonstationary signals & Increase computational time. \\
\hline $\begin{array}{l}\text { Fast Fourier Transform } \\
\text { (FFT) }\end{array}$ & $\begin{array}{l}\text { - } \quad \text { It works well for stationary signals. } \\
\text { - } \quad \text { A powerful method of frequency analysis. }\end{array}$ & $\begin{array}{l}\text { - Not applicable for nonstationary signals. } \\
\text { Unable to measure both time and } \\
\text { frequency. } \\
\text { It suffers from large noise sensitivity. } \\
\text { Poor time localization makes it not } \\
\text { suitable for all kinds of applications. }\end{array}$ \\
\hline $\begin{array}{l}\text { Wavelet Transformations } \\
\text { (WT) }\end{array}$ & $\begin{array}{l}\text { Suitable for nonstationary signals. } \\
\text { Able to analyze the signal in the time and } \\
\text { frequency domain. } \\
\text { Capable of analyzing signals with } \\
\text { discontinuities through variable window size. } \\
\text { It can analyze signals both in time and } \\
\text { frequency domains. } \\
\text { Can extract energy, distance or clusters etc. }\end{array}$ & $\begin{array}{l}\text { - Lacking specific methodology to apply } \\
\text { to pervasive noise } \\
\text { - Lacking specific methodology to apply } \\
\text { WT to the pervasive noise. } \\
\text { - Performance limited by Heisenberg } \\
\text { Uncertainty. }\end{array}$ \\
\hline
\end{tabular}

\section{CONCLUSIONS}

In this study, several studies have been reviewed on the classification of emotions based on physiological cues using brain signals (EEG), and the latest and most commonly used techniques in studies have been summarized for feature extraction, such as FFT, PSD, WT, DWT, 2D-CNN, etc. Also, most of the physiological sentiment datasets were summarized, including the DEAP dataset, the MAHNOB-HCI dataset, the SEED dataset, and the GAMEEMO dataset.

We focused on recent techniques and methods for classifying emotions, especially deep learning algorithms used to classify emotions. We also chose different types of emotion classification models: the negative and positive emotions model or the valence-arousal emotion model.

We noticed that deep learning techniques to extract features from EEG signals achieved better results than other traditional methods. For example: if we make a comparison of the results obtained in the articles we have reviewed, we will arrive at the following:
To make the comparison fair, we chose the same dataset (DEAP) and the same emotions model (arousal-valence model), so the studies [16, 23, 26, 29, 38] used traditional methods to extract the features and achieved the accuracy of (75.10\%, 86.35\%, 74.62\%, 92.87\%, 89.84, and 92.36\%), respectively. While the studies [19, 22, 25, 27, 28] were used the deep learning methods to extract the features, and achieved the accuracy of $(93 \%, 90.15 \%, 93 \%, 93.06 \%$, and $97.11 \%)$, respectively. You can note the superiority of deep learning techniques in extracting features from EEG brain signals.

We noticed that the EEG helps in different fields and can be developed in many areas, especially in health applications or applications of human-computer interaction, despite the difficulty of processing the EEG signal. Still, many incentives may inspire researchers to develop this broad field.

We have made a great effort to cover the most recent studies in this field, especially feature extraction techniques. We have made hard efforts to cover the most recent methods that have been used in literature. We hope that this review will guide researchers working on EEG and signal processing (Table 5).

Table 5. Emotion recognition recent studies based on EEG

\begin{tabular}{|c|c|c|c|c|c|c|c|c|}
\hline Ref. & Emotions & Method & Dataset & Stimuli & $\begin{array}{c}\text { Recorded } \\
\text { signals }\end{array}$ & Classifier & Year & Results \\
\hline$[2]$ & $\begin{array}{l}\text { Negative- } \\
\text { positive, } \\
\text { Valence- } \\
\text { Arousal }\end{array}$ & $\begin{array}{c}\text { Statistical features, DWT, Hjorth } \\
\text { features, Shannon entropy, } \\
\text { logarithmic energy entropy, } \\
\text { sample entropy, multiscale } \\
\text { entropy }\end{array}$ & GAMEEMO & $\begin{array}{l}\text { Video } \\
\text { game }\end{array}$ & $\begin{array}{c}\text { EEGs } \\
\text { from } 28 \\
\text { individual }\end{array}$ & $\begin{array}{c}\text { MLPNN, SVM, } \\
\text { K-NN }\end{array}$ & 2020 & $\begin{array}{c}\text { Good performance } \\
\text { with both models, with } \\
\text { an accuracy of } 80 \% \text { in } \\
\text { some channels }\end{array}$ \\
\hline
\end{tabular}




\begin{tabular}{|c|c|c|c|c|c|c|c|c|}
\hline [31] & $\begin{array}{l}\text { Negative- } \\
\text { positive }\end{array}$ & Spectral entropy & GAMEEMO & $\begin{array}{l}\text { Video } \\
\text { game }\end{array}$ & $\begin{array}{c}\text { EEGs } \\
\text { from } 28 \\
\text { individual } \\
\end{array}$ & $\begin{array}{l}\text { bidirectional } \\
\text { LSTM }\end{array}$ & 2020 & $76.91 \%$ \\
\hline \multirow{3}{*}[16]{} & \multirow{3}{*}{$\begin{array}{l}\text { Arousal- } \\
\text { Valence }\end{array}$} & \multirow{3}{*}{$\begin{array}{l}\text { Time-domain: statistical methods, } \\
\text { Frequency domain: PSD, Time- } \\
\text { Frequency domain: HHS }\end{array}$} & DEAP & $\begin{array}{l}\text { Video } \\
\text { clips }\end{array}$ & $\begin{array}{c}\text { EEGs } \\
\text { from } 32 \\
\text { individual } \\
\end{array}$ & \multirow{3}{*}{$\begin{array}{c}\text { DBN, DBN- } \\
\text { CRF } \\
\text { DBN-GC, } \\
\text { DBN-GC-CRF }\end{array}$} & \multirow{3}{*}{2020} & \multirow{3}{*}{$\begin{array}{l}\text { The best accuracy } \\
\text { obtained from the } \\
\text { DBN-GC-CRF } \\
\text { classifier is } 83.46 \% \\
\text { using the SEED dataset }\end{array}$} \\
\hline & & & SEED & $\begin{array}{l}\text { films } \\
\text { clips }\end{array}$ & $\begin{array}{c}\text { EEGs } \\
\text { from } 15 \\
\text { individual } \\
\end{array}$ & & & \\
\hline & & & AMIGOS & $\begin{array}{l}\text { short } \\
\text { and } \\
\text { long } \\
\text { videos }\end{array}$ & $\begin{array}{l}\text { Individual } \\
\text { and } 4 \\
\text { people } \\
\text { group }\end{array}$ & & & \\
\hline [17] & $\begin{array}{l}\text { Positive and } \\
\text { negative } \\
5 \text { emotions } \\
\text { from Images } \\
\text { and } 7 \text { basics } \\
\text { from videos } \\
\end{array}$ & $\begin{array}{c}\text { Spectral data, } \\
\text { inter-hemispheric asynchrony }\end{array}$ & $\begin{array}{l}\text { IAPS, } \\
\text { English } \\
\text { version of the } \\
\text { FilmStim }\end{array}$ & $\begin{array}{l}\text { Images, } \\
\text { Videos, } \\
\text { both }\end{array}$ & $\begin{array}{l}\text { EEGs } \\
\text { from } 18 \\
\text { individual }\end{array}$ & $\begin{array}{l}\text { K-NN, LR, NB, } \\
\text { SVM }\end{array}$ & 2020 & $\begin{array}{c}\text { The team obtained an } \\
\text { accuracy of } 95.49 \% \text { by } \\
\text { using the SVM } \\
\text { classifier for } \\
\text { combining images and } \\
\text { videos as stimuli } \\
\end{array}$ \\
\hline [18] & Relax, Stress & $\begin{array}{c}\text { Power spectral density using Fast } \\
\text { Fourier Transform } \\
\text { sub-band power ratio } \\
\end{array}$ & physio bank & $\begin{array}{l}\text { during } \\
\text { work }\end{array}$ & $\begin{array}{c}\text { EEGs } \\
\text { from } 36 \\
\text { individual } \\
\end{array}$ & KNN, SVM & 2020 & $\begin{array}{l}\text { Accuracy reached } \\
99.42 \% \text { of the FP1 } \\
\text { channel }\end{array}$ \\
\hline \multirow{2}{*}{ [19] } & \multirow{2}{*}{$\begin{array}{l}\text { Arousal- } \\
\text { Valence }\end{array}$} & \multirow{2}{*}{ ACRNN technique } & DEAP & $\begin{array}{l}\text { Video } \\
\text { clips }\end{array}$ & $\begin{array}{c}\text { EEGs } \\
\text { from } 32 \\
\text { individual } \\
\end{array}$ & \multirow{2}{*}{$\begin{array}{c}\text { ACRNN, } \\
\text { CNN, } \\
\text { RNN, } \\
\text { A-CNN-RNN }\end{array}$} & \multirow{2}{*}{2020} & \multirow{2}{*}{$\begin{array}{c}\text { DEAP }=93 \% \\
\text { DREAMER }=97 \%\end{array}$} \\
\hline & & & DREAMER & $\begin{array}{l}\text { film } \\
\text { clips }\end{array}$ & $\begin{array}{c}\text { EEGs } \\
\text { from } 23 \\
\text { individual } \\
\end{array}$ & & & \\
\hline [20] & $\begin{array}{l}\text { stress and } \\
\quad \text { calm }\end{array}$ & TE features, HOG+TE features & DEAP & $\begin{array}{l}\text { Video } \\
\text { clips }\end{array}$ & $\begin{array}{c}\text { EEGs } \\
\text { from } 32 \\
\text { individual } \\
\end{array}$ & SVM & 2020 & $\begin{array}{l}\mathrm{GC}+\mathrm{HOG}=88.93 \% \\
\mathrm{TE}+\mathrm{HOG}=95.21 \%\end{array}$ \\
\hline [48] & $\begin{array}{l}\text { Low arousal } \\
\text { and high } \\
\text { arousal }\end{array}$ & 1D-CNN, RP, DE & - & $\begin{array}{l}\text { game- } \\
\text { playing }\end{array}$ & $\begin{array}{c}\text { EEGs } \\
\text { from } 18 \\
\text { individual } \\
\end{array}$ & $\begin{array}{l}\text { TSception, } \\
\text { LSTM } \\
\text { SVM } \\
\end{array}$ & 2020 & 86.03 using TSception \\
\hline [21] & 5 Emotion & $\begin{array}{l}\text { DBN, EDA, PPG, and EMG based } \\
\text { on power spectral density (PSD) }\end{array}$ & DEAP & $\begin{array}{l}\text { Video } \\
\text { clips }\end{array}$ & $\begin{array}{c}\text { EEGs } \\
\text { from } 32 \\
\text { individual } \\
\end{array}$ & FGSVM & 2019 & $\begin{array}{c}\text { Happy Emotions are } \\
\text { classified } 100 \% \\
\text { accurately. }\end{array}$ \\
\hline [22] & $\begin{array}{l}\text { Arousal- } \\
\text { Valence }\end{array}$ & Multi-column structure & DEAP & $\begin{array}{l}\text { Video } \\
\text { clips }\end{array}$ & $\begin{array}{c}\text { EEGs } \\
\text { from } 32 \\
\text { individual } \\
\end{array}$ & $\begin{array}{l}\text { multi-olumn } \\
\text { CNN }\end{array}$ & 2019 & $\begin{array}{l}\text { Valence }=90.01 \% \\
\text { Arousal }=90.65 \%\end{array}$ \\
\hline [23] & $\begin{array}{l}\text { Arousal- } \\
\text { Valence }\end{array}$ & $\begin{array}{c}\text { Signal Framing, Frequency Band } \\
\text { Power (FBP), Pearson Correlation } \\
\text { Coefficient (PCC) }\end{array}$ & DEAP & $\begin{array}{l}\text { Video } \\
\text { clips }\end{array}$ & $\begin{array}{c}\text { EEGs } \\
\text { from } 32 \\
\text { individual } \\
\end{array}$ & LSTM & 2019 & $\begin{array}{l}\text { Valence }=81.10 \% \\
\text { Arousal }=74.38 \%\end{array}$ \\
\hline [24] & $\begin{array}{l}\text { negative } \\
\text { stress }\end{array}$ & $\begin{array}{c}\text { Amplitude-aware permutation } \\
\text { entropy, } \\
\text { Quadratic sample entropy, } \\
\text { Multiscale Entropy, } \\
\text { Composite Multiscale, } \\
\text { Statistical Study } \\
\text { CMQSE+CMAAPE }\end{array}$ & DEAP & $\begin{array}{l}\text { Video } \\
\text { clips }\end{array}$ & $\begin{array}{l}\text { EEGs } \\
\text { from } 32 \\
\text { individual }\end{array}$ & SVM, DT & 2019 & $86.35 \%$ \\
\hline [25] & $\begin{array}{l}\text { Arousal- } \\
\text { Valence }\end{array}$ & 3D-CNN & DEAP & $\begin{array}{l}\text { Video } \\
\text { clips }\end{array}$ & $\begin{array}{l}\text { EEGs } \\
\text { from } 32 \\
\text { individual }\end{array}$ & $\begin{array}{l}\text { 3D-CNN, } \\
\text { bagging, } \\
\text { stacking, Mask- } \\
\text { R-CNN }\end{array}$ & 2020 & $\begin{array}{c}\text { the best accuracy from } \\
\text { stacking technique } \\
\text { Valence }=96.13 \% \\
\text { Arousal }=96.79 \%\end{array}$ \\
\hline [26] & $\begin{array}{l}\text { Arousal- } \\
\text { Valence }\end{array}$ & $\begin{array}{l}\text { Random subset feature selection } \\
\text { (RSFS), sequential floating } \\
\text { forward selection (SFFS), and } \\
\text { sequential forward selection (SFS) }\end{array}$ & DEAP & $\begin{array}{l}\text { Video } \\
\text { clips }\end{array}$ & $\begin{array}{l}\text { EEGs } \\
\text { from } 32 \\
\text { individual }\end{array}$ & SVM & 2020 & $\begin{array}{l}\text { The results they } \\
\text { obtained showed that } \\
\text { RSFS performed }\end{array}$ \\
\hline [27] & $\begin{array}{l}\text { Arousal- } \\
\text { Valence }\end{array}$ & 2D-CNN, LSTM & DEAP & $\begin{array}{l}\text { Video } \\
\text { clips }\end{array}$ & $\begin{array}{c}\text { EEGs } \\
\text { from } 32 \\
\text { individual } \\
\end{array}$ & CRNN & 2020 & $\begin{array}{l}\text { Valence }=91.95 \% \\
\text { Arousal }=93.06 \%\end{array}$ \\
\hline \multirow[b]{2}{*}[28]{} & \multirow[b]{2}{*}{$\begin{array}{l}\text { Arousal- } \\
\text { Valence }\end{array}$} & \multirow{2}{*}{$\begin{array}{c}\text { Regional and asymmetric } \\
\text { Convolutional Neural Network } \\
\text { (RACNN) }\end{array}$} & DEAP & $\begin{array}{l}\text { Video } \\
\text { clips }\end{array}$ & $\begin{array}{c}\text { EEGs } \\
\text { from } 32 \\
\text { individual } \\
\end{array}$ & \multirow{2}{*}{$\begin{array}{l}\text { RACNN, 2D- } \\
\text { CNN, MLP, } \\
\text { DE+SVM, } \\
\text { DE+KNN }\end{array}$} & \multirow[b]{2}{*}{2020} & \multirow{2}{*}{$\begin{array}{c}\text { Best accuracy obtained } \\
\text { using a RACNN } \\
\text { DEAP dataset: } \\
\text { Valence }=96.65 \% \\
\text { Arousal }=97.11 \% \\
\text { DREAMER dataset: } \\
\text { Valence }=95.55 \% \\
\text { Arousal }=97.01 \%\end{array}$} \\
\hline & & & DREAMER & $\begin{array}{l}\text { film } \\
\text { clips }\end{array}$ & $\begin{array}{l}\text { EEGs } \\
\text { from } 23 \\
\text { individual }\end{array}$ & & & \\
\hline [29] & $\begin{array}{l}\text { Arousal- } \\
\text { Valence }\end{array}$ & $\begin{array}{c}\text { Discrete Wavelet, transform, } \\
\text { wavelet entropy, wavelet energy }\end{array}$ & DEAP & $\begin{array}{l}\text { Video } \\
\text { clips }\end{array}$ & $\begin{array}{c}\text { EEGs } \\
\text { from } 32 \\
\text { individual } \\
\end{array}$ & $\begin{array}{l}\text { MMResLSTM, } \\
\text { LSTM, } \\
\text { residual LSTM } \\
\end{array}$ & 2019 & $\begin{array}{c}\text { MMResLSTM: } \\
\text { Valence }=92.3 \% \\
\text { Arousal }=92.87 \%\end{array}$ \\
\hline [58] & $\begin{array}{l}\text { negative } \\
\text { emotional } \\
\text { recognition }\end{array}$ & $\begin{array}{l}\text { Frequency-Point Based on PSD, } \\
\text { Asymmetry in Frequency Point of } \\
\text { Electrode Pairs, Relative Band } \\
\text { Power (Based on PSD), } \\
\text { Asymmetry in Band Power of } \\
\text { Electrode Pairs (Based on PSD), } \\
\text { Relative Band Power Based on } \\
\end{array}$ & DEAP & $\begin{array}{l}\text { Video } \\
\text { clips }\end{array}$ & $\begin{array}{c}\text { EEGs } \\
\text { from } 32 \\
\text { individual }\end{array}$ & $\begin{array}{l}\text { SVM } \\
\text { MLP }\end{array}$ & 2019 & $\begin{array}{c}\text { The proposed method } \\
\text { achieved an accuracy } \\
\text { of } 94 \% \text {. }\end{array}$ \\
\hline
\end{tabular}


DWT, Asymmetry in Band Power

of Electrode Pairs (Based on

Wavelet), Entropy of Band Power (Based on Wavelet)

\begin{tabular}{|c|c|c|c|c|c|c|c|c|}
\hline \multirow[b]{2}{*}{ [38] } & \multirow[b]{2}{*}{$\begin{array}{l}\text { Arousal- } \\
\text { Valence }\end{array}$} & \multirow[b]{2}{*}{$\begin{array}{c}\text { Statistical features (SF), } \\
\text { wavelet transform (WT), } \\
\text { power spectral entropy (PSE), } \\
\text { higher-order crossing (HOC), and } \\
\text { higher-order spectral (HOS). }\end{array}$} & \multirow[b]{2}{*}{$\begin{array}{l}\text { MAHNOB- } \\
\text { HCI }\end{array}$} & \multirow{2}{*}{$\begin{array}{l}\text { Video } \\
\text { clips } \\
\\
\text { Movies } \\
\text { and } \\
\text { Pictures }\end{array}$} & \multirow{2}{*}{$\begin{array}{c}\text { EEGs } \\
\text { from } 32 \\
\text { individual } \\
\\
\text { EEGs } \\
\text { from } 30 \\
\text { individual }\end{array}$} & \multirow[b]{2}{*}{$\begin{array}{l}\text { K-NN, NB, } \\
\text { SVM }\end{array}$} & \multirow[b]{2}{*}{2018} & \multirow{2}{*}{$\begin{array}{c}\text { The best accuracy } \\
\text { using K-NN classifier } \\
\text { and statistical method } \\
\text { DEAP dataset: } \\
\text { Valence }=89.61 \% \\
\text { Arousal }=89.84 \% \\
\text { MAHNOB-HCI } \\
\text { dataset: } \\
\text { Valence }=94.6 \% \\
\text { Arousal }=94 \%\end{array}$} \\
\hline & & & & & & & & \\
\hline [37] & $\begin{array}{l}\text { stress } \\
\text { recognition }\end{array}$ & $\begin{array}{c}\text { Time Domain, Frequency } \\
\text { Domain, Neuroanatomical } \\
\text { Features: Frontal EEG Asymmetry }\end{array}$ & $\begin{array}{c}\text { DEAP } \\
\text { Construction } \\
\text { Workers' } \\
\text { EEG }\end{array}$ & $\begin{array}{l}\text { During } \\
\text { work }\end{array}$ & $\begin{array}{c}\begin{array}{c}\text { EEGs } \\
\text { from } 32 \\
\text { individual }\end{array} \\
\begin{array}{c}\text { EEGs } \\
\text { from } 7 \\
\text { individual }\end{array} \\
\end{array}$ & $\begin{array}{c}\text { OMTL- } \\
\text { VonNeuman }\end{array}$ & 2018 & $\begin{array}{c}\text { DEAP }=71.1 \% \\
\text { Construction } \\
\text { Workers' }=77.6 \%\end{array}$ \\
\hline [71] & $\begin{array}{l}\text { four basic } \\
\text { emotions } \\
\text { (happy, } \\
\text { calm, sad, } \\
\text { and fear) }\end{array}$ & Approximate entropy & - & $\begin{array}{l}\text { Video } \\
\text { clips }\end{array}$ & $\begin{array}{l}\text { EEGs } \\
\text { from } 10 \\
\text { individual }\end{array}$ & DBN-SVM & 2018 & $83.34 \%$ \\
\hline [30] & $\begin{array}{l}\text { Arousal- } \\
\text { Valence }\end{array}$ & Statistical parameter & DEAP & $\begin{array}{l}\text { Video } \\
\text { clips }\end{array}$ & $\begin{array}{l}\text { EEGs } \\
\text { from } 32 \\
\text { individual }\end{array}$ & $\mathrm{DNN}, \mathrm{CNN}$ & 2017 & $\begin{array}{l}\text { The best performance } \\
\text { was obtained using the } \\
\text { CNN algorithm, with } \\
\text { an accuracy of } 81.41 \% \text {. }\end{array}$ \\
\hline [41] & $\begin{array}{l}\text { Happy, and } \\
\text { sad }\end{array}$ & $\begin{array}{c}\text { Time-domain, frequency-domain, } \\
\text { DWT }\end{array}$ & - & images & $\begin{array}{c}\text { EEGs } \\
\text { from } 22 \\
\text { individual } \\
\end{array}$ & ANN & 2017 & $\begin{array}{l}\text { The best accuracy is } \\
77.3 \% \text { using the DWT } \\
\text { method }\end{array}$ \\
\hline [32] & $\begin{array}{l}\text { Positive vs. } \\
\text { negative vs. } \\
\text { neutral, } \\
\text { High arousal } \\
\text { vs. low } \\
\text { arousal }\end{array}$ & FFT & - & $\begin{array}{l}\text { film } \\
\text { clips }\end{array}$ & $\begin{array}{l}\text { EEGs } \\
\text { from } 27 \\
\text { individual }\end{array}$ & K-NN, SVM & 2018 & $\begin{array}{c}2018 \quad \text { Positive vs. } \\
\text { Negative vs. neutral: } \\
\text { SVM=88\% } \\
\text { K-NN }=72 \% \\
\text { High arousal vs. low } \\
\text { arousal } \\
\text { SVM=96\% } \\
\text { K-NN=84\% }\end{array}$ \\
\hline [57] & $\begin{array}{l}\text { Eight } \\
\text { emotional } \\
\text { states }\end{array}$ & $\begin{array}{l}\text { Multivariate synchro squeezing } \\
\text { transform (MSST), Short-time } \\
\text { Fourier transform (STFT), and } \\
\text { wavelet transform (WT) }\end{array}$ & DEAP & $\begin{array}{l}\text { Video } \\
\text { clips }\end{array}$ & $\begin{array}{c}\text { EEGs } \\
\text { from } 32 \\
\text { individual }\end{array}$ & SVM & 2019 & $93 \% \sim$ \\
\hline [33] & $\begin{array}{l}\text { Arousal- } \\
\text { Valence }\end{array}$ & $\begin{array}{c}\text { PSD } \\
\text { Frontal asymmetry }\end{array}$ & DEAP & $\begin{array}{l}\text { Video } \\
\text { clips }\end{array}$ & $\begin{array}{c}\text { EEGs } \\
\text { from } 32 \\
\text { individual } \\
\end{array}$ & DNN & 2017 & $\begin{array}{c}\text { Result: } 82.0 \% \text { for two } \\
\text { classes }\end{array}$ \\
\hline$[72]$ & $\begin{array}{l}4 \text { emotions } \\
\text { (happy, sad, } \\
\text { exciting, and } \\
\text { hate) }\end{array}$ & $\begin{array}{l}\text { Gabor wavelets, intrinsic mode } \\
\text { functions (IMFs) }\end{array}$ & DEAP & $\begin{array}{l}\text { Video } \\
\text { clips }\end{array}$ & $\begin{array}{c}\text { EEGs } \\
\text { from } 32 \\
\text { individual } \\
\end{array}$ & SVM & 2018 & $\begin{array}{l}93.86 \% \text { using Gabor } \\
\text { wavelets method }\end{array}$ \\
\hline$[47]$ & $\begin{array}{l}\text { Arousal- } \\
\text { Valence }\end{array}$ & $\begin{array}{c}\text { FFT, Statistical Features I, } \\
\text { Statistical Features II, Statistical } \\
\text { Features III }\end{array}$ & DEAP & $\begin{array}{l}\text { Video } \\
\text { clips }\end{array}$ & $\begin{array}{c}\text { EEGs } \\
\text { from } 32 \\
\text { individual } \\
\end{array}$ & SVM & 2019 & $92.36 \%$ \\
\hline
\end{tabular}

\section{REFERENCES}

[1] Chen, G., Zhang, X., Sun, Y., Zhang, J. (2020). Emotion feature analysis and recognition based on reconstructed EEG sources. IEEE Access, 8: 11907-11916. https://doi.org/10.1109/ACCESS.2020.2966144

[2] Alakus, T.B., Gonen, M., Turkoglu, I. (2020). Database for an emotion recognition system based on EEG signals and various computer games-GAMEEMO. Biomedical Signal Processing and Control, 60: 101951. https://doi.org/10.1016/j.bspc.2020.101951

[3] Choudhury, R.R. (2018). Technical perspective: Is your WiFi a sensor? Communications of the ACM, 61(9): 90. https://doi.org/10.1145/3236619

[4] Fan, Y., Lu, X., Li, D., Liu, Y. (2016). Video-based emotion recognition using CNN-RNN and C3D hybrid networks. In Proceedings of the 18th ACM International Conference on Multimodal Interaction, pp. 445-450. https://doi.org/10.1145/2993148.2997632

[5] Alarcao, S.M., Fonseca, M.J. (2017). Emotions recognition using EEG signals: A survey. IEEE Transactions on Affective Computing, 10(3): 374-393. https://doi.org/10.1109/TAFFC.2017.2714671

[6] Soroush, M.Z., Maghooli, K., Setarehdan, S.K., Nasrabadi, A.M. (2017). A review on EEG signals based emotion recognition. International Clinical Neuroscience Journal, 4(4): 118. https://doi.org/10.15171/icnj.2017.01

[7] Liu, Y. J., Yu, M., Zhao, G., Song, J., Ge, Y., Shi, Y. (2017). Real-time movie-induced discrete emotion recognition from EEG signals. IEEE Transactions on Affective Computing, 9(4): 550-562. https://doi.org/10.1109/TAFFC.2017.2660485

[8] Ekman, P. (1992). An argument for basic emotions. Cognition \& Emotion, 6(3-4): 169-200. https://doi.org/10.1080/02699939208411068

[9] Lang, P.J. (1995). The emotion probe: Studies of 
motivation and attention. American Psychologist, 50(5): 372. https://doi.org/10.1037/0003-066X.50.5.372

[10] Shu, L., Xie, J., Yang, M., Li, Z., Li, Z., Liao, D. (2018). A review of emotion recognition using physiological signals. Sensors, 18(7):

2074. https://doi.org/10.3390/s18072074

[11] Nagel, S. (2019). Towards a home-use BCI: fast asynchronous control and robust non-control state detection (Doctoral dissertation, Universität Tübingen). https://doi.org/10.15496/publikation-37739

[12] Casson, A.J., Yates, D.C., Smith, S.J., Duncan, J.S., Rodriguez-Villegas, E. (2010). Wearable electroencephalography. IEEE Engineering in Medicine and Biology Magazine, 29(3): 44-56. https://doi.org/10.1109/MEMB.2010.936545

[13] Bashivan, P., Rish, I., Heisig, S. (2016). Mental state recognition via wearable EEG. arXiv preprint arXiv:1602.00985.

[14] Horlings, R., Datcu, D., Rothkrantz, L.J. (2008). Emotion recognition using brain activity. In Proceedings of the 9th International Conference on Computer Systems and Technologies and Workshop for $\mathrm{PhD}$ Students in Computing, pp. II-1.

[15] Gao, Y., Lee, H.J., Mehmood, R.M. (2015). Deep learninig of EEG signals for emotion recognition. In 2015 IEEE International Conference on Multimedia \& Expo Workshops (ICMEW), pp. 1-5. https://doi.org/10.1109/ICMEW.2015.7169796

[16] Chao, H., Liu, Y. (2020). Emotion recognition from multi-channel EEG signals by exploiting the deep beliefconditional random field framework. IEEE Access, 8: 33002-33012. https://doi.org/10.1109/ACCESS.2020.2974009

[17] Sharan, R.V., Berkovsky, S., Taib, R., Koprinska, I., Li, J. (2020). Detecting personality traits using interhemispheric asynchrony of the brainwaves. In 2020 42nd Annual International Conference of the IEEE Engineering in Medicine \& Biology Society (EMBC), pp. 62-65.

https://doi.org/10.1109/EMBC44109.2020.9176108

[18] Priya, T.H., Mahalakshmi, P., Naidu, V.P.S., Srinivas, M. (2020). Stress detection from EEG using power ratio. In 2020 International Conference on Emerging Trends in Information Technology and Engineering (ic-ETITE), pp. 1-6. https://doi.org/10.1109/ic-ETITE47903.2020.401

[19] Tao, W., Li, C., Song, R., Cheng, J., Liu, Y., Wan, F., Chen, X. (2020). EEG-based emotion recognition via channel-wise attention and self attention. IEEE Transactions on Affective Computing. https://doi.org/10.1109/TAFFC.2020.3025777

[20] Gao, Y., Wang, X., Potter, T., Zhang, J., Zhang, Y. (2020). Single-trial EEG Emotion recognition using granger causality/transfer entropy analysis. Journal of Neuroscience $\quad$ Methods, 346: 108904. https://doi.org/10.1016/j.jneumeth.2020.108904

[21] Hassan, M.M., Alam, M.G.R., Uddin, M.Z., Huda, S., Almogren, A., Fortino, G. (2019). Human emotion recognition using deep belief network architecture. Information Fusion, 51: 10-18. https://doi.org/10.1016/j.inffus.2018.10.009

[22] Yang, H., Han, J., Min, K. (2019). A multi-column CNN model for emotion recognition from EEG signals. Sensors, $19(21)$ : 4736. https://doi.org/10.3390/s19214736
[23] Xing, X., Li, Z., Xu, T., Shu, L., Hu, B., Xu, X. (2019). SAE+ LSTM: A New framework for emotion recognition from multi-channel EEG. Frontiers in Neurorobotics, 13 : 37. https://doi.org/10.3389/fnbot.2019.00037

[24] Martínez-Rodrigo, A., García-Martínez, B., Alcaraz, R., González, P., Fernández-Caballero, A. (2019). Multiscale entropy analysis for recognition of visually elicited negative stress from EEG recordings. International Journal of Neural Systems, 29(2): 1850038. https://doi.org/10.1142/S0129065718500387

[25] Salama, E.S., El-Khoribi, R.A., Shoman, M.E., Shalaby, M.A.W. (2021). A 3D-convolutional neural network framework with ensemble learning techniques for multimodal emotion recognition. Egyptian Informatics Journal, 22(2): 167-176. https://doi.org/10.1016/j.eij.2020.07.005

[26] Goshvarpour, A., Goshvarpour, A. (2020). A novel approach for EEG electrode selection in automated emotion recognition based on Lagged Poincare's Indices and sLORETA. Cognitive Computation, 12(3): 602-618. https://doi.org/10.1007/s12559-019-09699-Z

[27] Liao, J., Zhong, Q., Zhu, Y., Cai, D. (2020). Multimodal physiological signal emotion recognition based on convolutional recurrent neural network. In IOP Conference Series: Materials Science and Engineering 782(3): $\quad 032005 . \quad$ https://doi.org/10.1088/1757899X/782/3/032005

[28] Cui, H., Liu, A., Zhang, X., Chen, X., Wang, K., Chen, X. (2020). EEG-based emotion recognition using an endto-end regional-asymmetric convolutional neural network. Knowledge-Based Systems, 205: 106243. https://doi.org/10.1016/j.knosys.2020.106243

[29] Ma, J., Tang, H., Zheng, W.L., Lu, B.L. (2019). Emotion recognition using multimodal residual LSTM network. In Proceedings of the 27th ACM International Conference on Multimedia, pp. 176-183. https://doi.org/10.1145/3343031.3350871

[30] Tripathi, S., Acharya, S., Sharma, R.D., Mittal, S., Bhattacharya, S. (2017). Using deep and convolutional neural networks for accurate emotion classification on DEAP dataset. In Twenty-ninth IAAI conference.

[31] Alakus, T.B., Turkoglu, I. (2020). Emotion recognition with deep learning using GAMEEMO data set. Electronics Letters, 56(25): 1364-1367. https://doi.org/10.1049/el.2020.2460

[32] Tarnowski, P., Kołodziej, M., Majkowski, A., Rak, R.J. (2018). Combined analysis of GSR and EEG signals for emotion recognition. In 2018 International Interdisciplinary PhD Workshop (IIPhDW), pp. 137-141. https://doi.org/10.1109/IIPHDW.2018.8388342

[33] Al-Nafjan, A., Hosny, M., Al-Wabil, A., Al-Ohali, Y. (2017). Classification of human emotions from electroencephalogram (EEG) signal using deep neural network. International Journal of Advanced Computer Science and Applications, 8(9): 419-425. https://doi.org/10.14569/ijacsa.2017.080955

[34] Koelstra, S., Muhl, C., Soleymani, M., Lee, J.S., Yazdani, A., Ebrahimi, T. (2011). DEAP: A database for emotion analysis; Using physiological signals. IEEE Transactions on Affective Computing, 3(1): 18-31. https://doi.org/10.1109/T-AFFC.2011.15

[35] Soleymani, M., Lichtenauer, J., Pun, T., Pantic, M. (2011). A multimodal database for affect recognition and 
implicit tagging. IEEE Transactions on Affective Computing, 3(1): 42-55. https://doi.org/10.1109/TAFFC.2011.25

[36] Zheng, W.L., Lu, B.L. (2015). Investigating critical frequency bands and channels for EEG-based emotion recognition with deep neural networks. IEEE Transactions on Autonomous Mental Development, 7(3): 162-175. https://doi.org/10.1109/TAMD.2015.2431497

[37] Jebelli, H., Khalili, M.M., Lee, S. (2018). A continuously updated, computationally efficient stress recognition framework using electroencephalogram (EEG) by applying online multitask learning algorithms (OMTL). IEEE Journal of Biomedical and Health Informatics, 23(5):

1928-1939. https://doi.org/10.1109/JBHI.2018.2870963

[38] Piho, L., Tjahjadi, T. (2018). A mutual information based adaptive windowing of informative EEG for emotion recognition. IEEE Transactions on Affective Computing, 11(4): $722-735$ https://doi.org/10.1109/TAFFC.2018.2840973

[39] Amin, H.U., Malik, A.S., Ahmad, R.F., Badruddin, N., Kamel, N., Hussain, M., Chooi, W.T. (2015). Feature extraction and classification for EEG signals using wavelet transform and machine learning techniques. Australasian Physical \& Engineering Sciences in Medicine, $\quad 38(1)$ : 139-149. https://doi.org/10.1007/s13246-015-0333-x

[40] Chen, D., Wan, S., Xiang, J., Bao, F. S. (2017). A highperformance seizure detection algorithm based on Discrete Wavelet Transform (DWT) and EEG. PloS One, 12(3): https://doi.org/10.1371/journal.pone.0173138

[41] Ang, A.Q.X., Yeong, Y.Q., Wee, W. (2017). Emotion classification from EEG signals using time-frequencyDWT features and ANN. Journal of Computer and Communications, 5(3): 75-79. https://doi.org/10.4236/jcc.2017.53009

[42] Subasi, A. (2007). EEG signal classification using wavelet feature extraction and a mixture of expert model. Expert Systems with Applications, 32(4): 1084-1093. https://doi.org/10.1016/j.eswa.2006.02.005

[43] Murugappan, M., Murugappan, S. (2013). Human emotion recognition through short time Electroencephalogram (EEG) signals using Fast Fourier Transform (FFT). In 2013 IEEE 9th International Colloquium on Signal Processing and its Applications, pp. 289-294 https://doi.org/10.1109/CSPA.2013.6530058

[44] Saxena, A., Tripathi, K., Khanna, A., Gupta, D., Sundaram, S. (2020). Emotion detection through EEG signals using FFT and machine learning techniques. In: Khanna A., Gupta D., Bhattacharyya S., Snasel V., Platos J., Hassanien A. (eds) International Conference on Innovative Computing and Communications. Advances in Intelligent Systems and Computing, vol 1087. Springer, Singapore. https://doi.org/10.1007/978-98115-1286-5_46

[45] Zhu, C., Huang, H., Liu, H., Song, C., Ma, F. (2014). Online vibration monitoring and diagnosing a multimegawatt wind turbine gearbox. In Proc. of the International Gear Conference, pp. 1089-1098. https://doi.org/10.1533/9781782421955.1089

[46] Islam, M., Ahmed, T., Mostafa, S.S., Yusuf, M.S.U., Ahmad, M. (2013). Human emotion recognition using frequency \& statistical measures of EEG signal. In 2013 International Conference on Informatics, Electronics and Vision (ICIEV), pp. 1-6. https://doi.org/10.1109/ICIEV.2013.6572658

[47] George, F.P., Shaikat, I.M., Ferdawoos, P.S., Parvez, M.Z., Uddin, J. (2019). Recognition of emotional states using EEG signals based on time-frequency analysis and SVM classifier. International Journal of Electrical \& Computer Engineering, 9(2): 1012-1020. http://doi.org/10.11591/ijece.v9i2.pp1012-1020

[48] Ding, Y., Robinson, N., Zeng, Q., Chen, D., Wai, A.A.P., Lee, T.S., Guan, C. (2020). Tsception: A deep learning framework for emotion detection using EEG. In 2020 International Joint Conference on Neural Networks (IJCNN), pp. 1-7. http://doi.org/10.1109/IJCNN48605.2020.9206750

[49] Wang, F., Wu, S., Zhang, W., Xu, Z., Zhang, Y., Wu, C., Coleman, S. (2020). Emotion recognition with convolutional neural network and EEG-based EFDMs. Neuropsychologia, 107506. https://doi.org/10.1016/j.neuropsychologia.2020.107506

[50] Wen, Z., Xu, R., Du, J. (2017). A novel convolutional neural networks for emotion recognition based on EEG signal. In 2017 International Conference on Security, Pattern Analysis, and Cybernetics (SPAC), pp. 672-677. https://doi.org 10.1109/SPAC.2017.8304360

[51] Abdullah, S., Nizwan, C.K.E., Nuawi, M.Z. (2009). A study of fatigue data editing using the Short-Time Fourier Transform (STFT). American Journal of Applied Sciences, $\quad 6(4)$ : 565. https://doi.org/10.3844/ajas.2009.565.575

[52] Bastos-Filho, T.F., Ferreira, A., Atencio, A.C., Arjunan, S., Kumar, D. (2012). Evaluation of feature extraction techniques in emotional state recognition. In 2012 4th International Conference on Intelligent Human Computer Interaction (IHCI), pp. 1-6. https://doi.org/10.1109/IHCI.2012.6481860

[53] Ng, W.B., Saidatul, A., Chong, Y.F., Ibrahim, Z. (2019). PSD-based features extraction for EEG signal during typing task. In IOP Conference Series: Materials Science and Engineering, 557(1): 012032.

[54] Nguyen, T.H., Chung, W.Y. (2019). Negative news recognition during social media news consumption using EEG. IEEE Access, 7: 133227-133236. https://doi.org/10.1109/ACCESS.2019.2941251

[55] Zebari, R., Abdulazeez, A., Zeebaree, D., Zebari, D., Saeed, J. (2020). A comprehensive review of dimensionality reduction techniques for feature selection and feature extraction. Journal of Applied Science and Technology Trends, 1(2): 56-70. https://doi.org/10.38094/jastt1224

[56] Priya, T.H., Mahalakshmi, P., Naidu, V.P.S., Srinivas, M (2020). Stress detection from EEG using power ratio. In 2020 International Conference on Emerging Trends in Information Technology and Engineering (ic-ETITE), pp 1-6. https://doi.org/10.1109/ic-ETITE47903.2020.401

[57] Ozel, P., Akan, A., Yilmaz, B. (2019). Synchrosqueezing transform based feature extraction from EEG signals for emotional state prediction. Biomedical Signal Processing and Control, 52: 152-161. https://doi.org/10.1016/j.bspc.2019.04.023

[58] Nguyen, T.H., Chung, W.Y. (2019). Negative news recognition during social media news consumption using EEG. IEEE Access, 7: 133227-133236. 
https://doi.org/10.1109/ACCESS.2019.2941251

[59] Liao, J., Zhong, Q., Zhu, Y., Cai, D. (2020). Multimodal physiological signal emotion recognition based on convolutional recurrent neural network. In IOP Conference Series: Materials Science and Engineering, 782(3): $\quad 032005 . \quad$ https://doi.org/10.1088/1757$899 \mathrm{X} / 782 / 3 / 032005$

[60] Shedeed, H.A., Issa, M.F., El-Sayed, S.M. (2013). Brain EEG signal processing for controlling a robotic arm. In 2013 8th International Conference on Computer Engineering \& Systems (ICCES), pp. 152-157. https://doi.org/10.1109/ICCES.2013.6707191

[61] Nafea, M., Abdul-Kadir, N.A., Harun, F.K.C. (2018). Brainwave-controlled system for smart home applications. In 2018 2nd International Conference on BioSignal Analysis, Processing and Systems (ICBAPS), pp. $75-80$. https://doi.org/10.1109/ICBAPS.2018.8527397

[62] Schelenz, P.D., Klasen, M., Reese, B., Regenbogen, C., Wolf, D., Kato, Y., Mathiak, K. (2013). Multisensory integration of dynamic emotional faces and voices: method for simultaneous EEG-fMRI measurements. Frontiers in Human Neuroscience, 7: 729. https://doi.org/10.3389/fnhum.2016.00624

[63] Srinivasan, N. (2007). Cognitive neuroscience of creativity: EEG based approaches. Methods, 42(1): 109116. https://doi.org/10.1016/j.ymeth.2006.12.008

[64] Alotaiby, T.N., Alshebeili, S.A., Alshawi, T., Ahmad, I., Abd El-Samie, F.E. (2014). EEG seizure detection and prediction algorithms: A survey. EURASIP J. Adv. Signal Process, 2014: 1-21. https://doi.org/10.1186/1687-6180-2014-183

[65] Krishnan, P.T., Raj, A.N.J., Balasubramanian, P., Chen, Y. (2020). Schizophrenia detection using MultivariateEmpirical Mode Decomposition and entropy measures from multichannel EEG signal. Biocybernetics and Biomedical Engineering, 40(3): 1124-1139. https://doi.org/10.1016/j.bbe.2020.05.008

[66] Spüler, M., Krumpe, T., Walter, C., Scharinger, C., Rosenstiel, W., Gerjets, P. (2017). Brain-computer interfaces for educational applications. In Informational Environments, pp. 177-201. https://doi.org/10.1007/9783-319-64274-1_8

[67] Oon, H.N., Saidatul, A., Ibrahim, Z. (2018). Analysis on Non-linear features of electroencephalogram (EEG) signal for neuromarketing application. In 2018 International Conference on Computational Approach in Smart Systems Design and Applications (ICASSDA), pp. 1-8. https://doi.org/10.1109/ICASSDA.2018.8477618

[68] Lakshmi, M.R., Prasad, T.V., Prakash, D.V.C. (2014). Survey on EEG signal processing methods. International Journal of Advanced Research in Computer Science and Software Engineering.

[69] Santhiya, P., Chitrakala, S. (2019). A survey on emotion recognition from EEG signals: Approaches, Techniques \& Challenges. In 2019 International Conference on Vision Towards Emerging Trends in Communication and Networking (ViTECoN), pp. 1-6. https://doi.org/10.1109/ViTECoN.2019.8899671

[70] Pham, T., Ma, W., Tran, D., Nguyen, P., Phung, D. (2013). A study on the feasibility of using EEG signals for authentication purpose. In International Conference on Neural Information Processing, pp. 562-569. https://doi.org/10.1007/978-3-642-42042-9_70

[71] Chen, T., Ju, S., Yuan, X., Elhoseny, M., Ren, F., Fan, M., Chen, Z. (2018). Emotion recognition using empirical mode decomposition and approximation entropy. Computers \& Electrical Engineering, 72: 383 392. https://doi.org/10.1016/j.compeleceng.2018.09.022

[72] Zamanian, H., Farsi, H. (2018). A new feature extraction method to improve emotion detection using EEG signals. ELCVIA: Electronic Letters on Computer Vision and Image $\quad$ Analysis, $17(1)$ : 29-44. https://doi.org/10.5565/rev/elcvia.1045 